\title{
An Ethnographic Study of Novice English Language Teachers' Challenges Faced While Teaching English as Foreign Language in Pakistan
}

\author{
Pirah Sapna Sanam \\ MS Scholar, Mehran University of Engineering \& Technology, Jamshoro \\ Syed Waqar Ali Shah \\ Lecturer, Mehran University of Engineering \& Technology, Jamshoro \\ Dr Habibullah Pathan \\ Associate Professor, Mehran University of Engineering \& Technology, Jamshoro \\ Chahat Batool Moomal Raza \\ MS Scholar, Mehran University of Engineering \& Technology, Jamshoro
}

\begin{abstract}
The study deals with the challenges that newly appointed L2 teachers encounter while teaching English in Public Sector University. There are a few ethnographical studies done in Pakistan that explore the challenges novice teachers face and the strategies they use to cope with these challenges while teaching in university classroom. The present study has taken place in University of Sindh Jamshoro. Qualitative research design has been used, the data collection instruments were classroom observations and semi-structured interviews. The participants were in-service L2 novice teachers; 5 teachers were observed while teaching in classroom, and two of them were interviewed. Purposive sampling was used in order to select the participants for this study. The data was analyzed through thematic data analysis. It was found that the novice teachers begin to face the challenges from the day of their employment due to absence of formal instructions on the first day of joining. Their challenges included cultural shock, large classes, level and educational background of the learners, outdated course, infrastructure, lack of resources and assessment.
\end{abstract}

Keywords: Ethnographical, Qualitative, Novice Teacher, Challenges, Public Sector University

DOI: $10.7176 / \mathrm{JLLL} / 80-04$

Publication date:June $30^{\text {th }} 2021$

\section{Introduction}

There is no certain or clear-cut definition of novice teachers in accordance with the literature, however the term 'Novice' is used for the beginning teachers in number of studies. Any teacher who is introduced to new cultural context or has newly started to teach can be a novice teacher (Farrell, 2012). Kim and Roth (2011) in their study maintained that a teacher said to be novice, who has less than five year experience. It is quite challenging for a novice teachers to cope with the diverse mind of multiple level at one place, and due to growing stress these teachers tend to quit their profession. The initial experiences of teachers related to teaching and the given opportunities to open up regarding issues they encounter while teaching in classroom are closely related to the success of novice teachers (Potton, 2006).

A number of studies suggest the initial teaching years of novice teacher are quite critical. Most of the novice teachers leave their job in their initial years, however many of these teachers survive and reach the professional development. Farrell (2012) proposed his study on the issues of Novice professionals conducted in TESOL Quarterly. The study was focused on the language development of novice-service; the transition period of novice teachers from their preparation to the very first years of teaching. He remarked that those novice teachers who cannot endure the reality shock for the first time in actual classroom. They tend to leave their teaching career during this period of time.

The policies proposed to address the structural or organizational problems regarding teacher education, do not provide guidelines in order to interpret issue comprehensively and understand them to develop the program respectively. The issues are not discussed or explained by underlying the causes rather identified and conversed in an isolated way. The teacher education issue originating from the local and international context, has never been taken under consideration with serious efforts in relation with schools, from the perspective of fresh knowledge.

\subsection{Research problem}

L2 teachers play most significant role in the language learning process of the learners. They face tremendous 
difficulties during the initial years of their teaching career. And they overcome these challenges in accordance their own pace. Most of the studies conducted in Pakistan and other contexts of the world are done quantitatively. Lee (2017) maintained that $71 \%$ of the studies conducted in North Korea on the challenges of novice teachers are based on quantitative approach. The present study uses Ethnographical approach in order to explore in-depth challenges faced by newly appointed L2 teachers while teaching in Public sector University.

\subsection{Research Question}

The present study intend to address following research question:

1. What are challenges L2 novice teachers encounter while teaching English as a foreign language in a public sector university?

\section{Literature Review}

Considering the challenges of newly appointed teachers in accordance with the literature review, a list of challenges that a language teacher face in Pakistan has been presented by the number of studies after discussing the issues in detail, it includes outdated teaching practices, students' traditional evolution ways uncertain national polices, unsuitable teaching stuff that leads to less development of skills, lack of resources (Warsi, 2004; Mirza, 2009; Mansoor, 2009; Siddiqui, 2002). In Pakistan the language is taught in a condition which is neither suitable for the language teachers nor language learners, moreover in order to adjust effectively in the institutes and the teaching profession, novice language teachers have to face numerous challenges due to such situations.

In order to report the critical issues of novice teachers in-depth and to contextualize the sociocultural manners, Lee (2017) conducted an ethnographical study in a Korean EFL independent school. The purpose of study was to reveal challenges faced by L2 novice teachers during their first year of teaching. It was found that foremost challenges the teachers faced included reality shock, unrealistic expectations due to previous teaching experience which affect the teaching practices and motivation of students to learn and practice the language.

Dayan et al. (2018) conducted study in the private schools of district Peshawar. It was a qualitative study. It was fond there is difference between theory and practice. Novice teachers found challenging the transition time period between pre-training and actual classroom teaching. They had to deal with the challenges such as; heavy work load, non-supportive staff, implementation of student centered pedagogies in large classes, dealing with learners' individual differences and interference of parents in school's affairs. While the participants tended to deal with these challenges by forming bond with the learners, implicating advanced models of lesson plans and by becoming inclusive for the school's culture.

Tahir and Qadir (2012) conducted their study in the higher secondary school Islamabad in order to explore the challenges of novice teacher's face. It was found that the novice teachers were facing numerous issues regarding culture of that organization such as: the administration was non-supportive, the relationship among the teachers weak, the role of staffroom was ineffective, teacher's self-perception was unstable and the academic resources were inadequate. In order to make the organizational culture beneficial for the novice teachers it was suggested that novice teachers should informed about the objectives of the organization, professional requirements, decrease the rate of conflict and in order to help newly appointed teachers Principal should play his/her role efficiently.

Ahmed et al. (2020) conducted his study in Public Sector Girls' secondary schools of Panjab, more specifically Okara and Pakpatan districts. The purpose of the study was to investigate the challenge that affect the novice female teachers' performance. It was found that because of the non-supportive attitude of head teachers, lack of pedagogical skills, disruptive attitude of the students and lack of conductive environment created hindrance for the novice female teachers' to perform in a better way. In order to perform in a better way and retain the jobs novice teachers, the study recommended to provide conductive environment of school and Head teachers' supportive attitude towards newly appointed teachers. A qualitative study was conducted in Public Sector schools of Lahore in order to explore the self-regulated challenges novice teachers created for themselves.

Saleem and Muhammad (2020) found that while implementing self-regulated strategies in order to cope with the classroom management create challenges for them for instance sometimes teachers' behaviors carried negative motions. Some of the participants believed that their challenges are created through high tendency in their anger, while other believed that their non-seriousness and snubbing towards teaching made their teaching practice challenging. Concerning the emotional management of novice teachers, the study recommended that the schools should develop a support mechanism in order to ensure professional developments of teachers and effective teaching learning classroom environment.

\section{Research methodology}

The present study has used qualitative research design. Creswell (2014) maintained that the qualitative approach supports the style of inductive study where researcher tend to focus on the importance of situation, its 
complexity and meaning. Usually data is collected through participants setting in this approach, while the analyzed inductively and carefully interpreted by the researcher. It is an ethnographical study. The difference between traditional and linguistic Ethnography is that the ethnographical inquiry either claims about language, communication or the social world.

Rampton et al. (2004) proposed that this world is being shaped to the significant degree with the help of language and linguistic ethnography. Moreover, through close analysis of situated language in use, linguistic ethnography helps in getting fundamental and distinctive insights of mechanism and dynamics in day to day life activity.

The next phase was the transcription of collected data. The verbal protocols were analyzed through open coding. And the interpretive process focused on the challenges experienced by the participants. The participants were L2 novice teachers of Public Sector University. The data was analyzed through thematic data analysis using thematic data analysis model Braun and Clarke (2006).

\subsection{Sampling and participants of the study}

The present study opted purposive sampling within sampling-criteria. The purposive sampling is the technique used to identify and choose the individuals or groups as participants with knowledge and experience related to the interest of respective phenomenon (Creswell, 2011). There were five in-service university teachers selected as participants for this study, three out of them were females and two males. Their qualification varied from bachelors to masters.

\subsection{Data collection and analysis}

The present study is an ethnographical study. So, the data collection instruments included observation and semi structured interviews. The participants were newly appointed in-service English language teachers. The classes of 5 participants were observed during the first phase of data collection, two classes of each teacher were observed during teaching language in university. Whereas in the second phase of data collection two teachers were interviewed in order to explore in-depth challenges encountered by novice teachers. The data was analyzed trough thematic data analysis using Braun and Clarke's data analysis model (2006). The data was familiarized by the researcher and then themes were generated after the initial coding was done. The validity and reliability of the themes was made sure. The themes were defined and named precisely and the finding were reported after interpreting the data.

\section{Findings and Discussion}

The findings of the study discovers that the challenges of novice teachers begins from the day they are hired and join the organization. About $(n=4,80 \%)$ teachers confessed that when they joined the institute as novice teachers, they were not given formal instructions or orientation. And each teacher had to deal with these challenges individually. However $10 \%$ teachers confessed that they are sure they have coped these challenges successfully

The learners' previous knowledge about language and language learning was problematic. They were habitual of teacher-centered method and were memorizing the language content instead of practicing or producing it. Almost confessed that the students' are weak in language skills and content. Because the outdated teaching methods and contents are taught in schools, and this is not only the issue of UoS but all over Pakistan. About $40 \%$ teachers reported that the level of students is much lower than a university student is expected. Students show their interest in improving their English language. When it comes to participate, only $10 \%$ students respond in class.

Most of the participants agreed to the fact that the university needs to update the prescribed course. T1 confessed that the prescribed course is outdated, neither it's practical nor worth teaching. Bughio (2013) maintained that the books that are prescribed to taught (i-e Howe, D.H, Kirkpatrick, T.A. and Kirkpatrick, D.L. English for Undergraduates, Karachi, O.U.P, wren and Martin's High School Grammar and Composition, Eastwood, John, Oxford Practice Grammar, Karachi, Oxford University Press, 2005) are outdated. As the theoretical changes have been occurred and many words' usage has been changed. Teachers confessed that they strive to develop the interest of the students and keep them motivated.

The large classes are the result of the huge enrollment in the universities due to increasing needs of the higher education. $(n=5,100 \%)$ teachers reported that they had horrifying first teaching experience in university class due to huge number of students. teacher were quite uncertain to manage about 200 students at once. The large class is one of the major issue that is accompanied by other tiny issues with it. Teachers found it challenging to take accurate attendance and make their class interactive in limited time.

Infrastructure plays important role in language teaching. About $(n=4,80 \%)$ teachers confessed that the infrastructure of the classroom adds to their challenges. The classrooms are wide and in auditorium setting with fixed seating arrangement. In order to manage the large classes teachers usually prefer group activities. And it is 
not possible to practice group activities in such classes, because the infrastructure of the classroom does not support it. Teachers of the current time prefer modern teaching strategies that includes the use of multimedia and audio-visual classes. However the university classroom lack the basic resources i-e the availability of mic or sound system. So, the lack resources is additional issue that teachers encounter.

Reviewing previously mentioned issues, assessment was comparatively prominent challenge teachers could not really resolved yet. T2 confessed that students use to show huge interest and concern for their work to be checked but it is not possible to accommodate all the needs of students in limited time. The additional challenges that reported in the current study includes: classroom managing, workload, adapting different teaching strategies, cultural shock, using Urdu and Sindhi language along with English as language of instruction according to need and level of the students respectively.

\section{Conclusion}

This study witnesses the issues of newly appointed in-service university teachers. According to literature review, the challenges of L2 novice university teachers are least researched in the context of Pakistan. Study shows that there is no any proper channel or committee organized that addresses the issues of novice teachers, neither orientation nor any direction is given to newly appointed teachers on initial days regarding respective institute. Teachers have to encounter the issues and cope with these individually. The current study explored the challenges teachers faced during their initial years of teaching. It was found that it took a while for a teacher to understand and adjust in the environment of the institute. Number of studies suggests that the Educational institutes need to associate with their teachers, say it psychologically or emotionally. The needs of both parties' (i-e teacher and the institute) should be fulfilled in contract agreement (Hunsaker \& Cook, 1986; Kotter, 1973; Schein, 1982). For instance in order to socialize successfully and effortlessly, the teachers would mold their teaching practices and skills in order to attain the objectives of the institute and in response the institute take care of the needs of the teachers.

The challenges that are encountered by the teachers stayed nearly unresolved, for instance classroom management due to lack of resources and the infrastructure of the classrooms. Teachers are bound to work within prevalent context, which does not provide supporting services and helpful infrastructure. It is not possible for teachers to achieve the objectives of curriculum under unsatisfactory physical conditions the classroom (O’Sullivan, 2002; Bantwini, 2010).

Generalized course is being used in all over the departments of the UoS. All 5 participant suggested that the prescribed course needs to be updated. Bughio (2013) maintained the prescribe course of Uos for compulsory English was last time updated in 2005. However the needs of the learners are changing with time.

While observing the language teachers teaching in university classes, it was found that the assessment of huge number of students was one of the prominent issue that remained unresolved regardless of the teaching experience of novice teachers had. Teachers most of the time delivered lecture and kept the class interactive, and interaction was limited to only those students who responded. Teacher confessed that they cannot assess students individually due to limited time. Teachers confessed that they still strive to assess students and record their progress. Those teachers who could managed to give extra time to the students, they facilitated the students with the platform of social media or giving extra time to the students outside of the class. But the strategies didn't work for all of the teacher. Numerous detailed studies conducted on the challenges of English language teachers discover a list of challenges includes lack of resources, unsuitable teaching methods, outdated teaching practices, traditional evolution ways of students and uncertain national polices (Siddiqui, 2002; Warsi, 2004; Mansoor, 2009; Mirza, 2009)

\section{References}

Ahmed, G., Faizi, W. U. N., \& Akbar, S. (2020). Challenges of Novice Teachers and Strategies to Cope at Secondary Level. Global Regional Review, 1, 403-416.

Bughio, F. A. (2013). Improving English language teaching in large classes at university level in Pakistan (Doctoral dissertation, University of Sussex).

Creswell, J. W. \& Plano Clark, V. L. (2011). Designing and conducting mixed methods research

(2nd ed.). Thousand Oaks, CA: SAGE

Dayan, U., Perveen, S., \& Khan, M. I. (2018). Transition from Pre-Service Training to Classroom: Experiences and Challenges of Novice Teachers in Pakistan. FWU Journal of Social Sciences, 12(2), 48.

Farrell, T. S. C. (2012). Novice-Service language teacher development: Bridging the gap between preservice and in-service education and development. TESOL Quarterly, 46(3), 435-449.

Hunsaker, P.L., \& Cook, C.W. (1986). Managing organizational behavior. Reading, PA: Addison-Wesley Publishing Co Inc.

Kim, K., \& Roth, G. (2011). Novice teachers and their acquisition of work-related information. Current

Kotter, J.P. (1973). The psychological contract: Managing the joining-up process. California Management 
Review, 15(3), 91-99.

Issues in Education, 14 (1). Retrieved from http://cie.asu.edu/

Lee, J. S. J. (2017). Hidden Challenges of Novice English Teachers in a Korean Independent School: Through an Ethnographic Lens. The Qualitative Report, 22(6), 1637-1652.

Mansoor, S. (2009). Regional languages of Pakistan: Issues and concerns for language planning in Higher Education. In S. Mansoor, A. Skiandar, N. Hussain, \& N.M. Ahsan (Eds.), Emerging issues in TEFL: Challenges for Asia (pp. 31- 58). Karachi: Oxford University Press.

Mirza, N. (2009). Mentoring: A concept for teacher development. In S. Mansoor, A. Skiandar, N. Hussain, \& N.M. Ahsan (Eds.), emerging issues in TEFL: Challenges for Asia (pp. 207-230). Karachi: Oxford University Press.

Saleem, A., \& Muhammad, D. Y. (2020). Negative Emotions and Self-Created Challenges of Novice PublicSchool Teachers in Managing Classroom. Journal of Elementary Education, 29(2), 178-195.

Siddiqui, S. (2002, August 19). English and our colonial past. Pakistan Observer.

Tahir, A., \& Qadir, S. A. (2012). Perspective of Organizational Cultural in Effective Teacher Socialization: A Study of Beginning English Teachers in Pakistan. Pakistaniaat: A Journal of Pakistan Studies, 4(2), 56-86.

Warsi, J. (2004). Conditions under which English is taught in Pakistan: An Applied Linguistic perspective. SARID Journal, 1(1), 1-9. 